\title{
DETC2015-46274
}

\section{GEAR TOOTH ROOT STRESSES OF A VERY HEAVILY LOADED GEAR PAIR - CASE STUDY: ORBITER BODY FLAP ACTUATOR PINION AND RING GEAR}

\author{
Timothy L. Krantz \\ Robert F. Handschuh \\ NASA \\ Cleveland, Ohio, 44145 \\ timothy.l.krantz@nasa.gov
}

\begin{abstract}
The space shuttle orbiter's body flap actuator gearing was assessed as a case study of the stresses for very heavily loaded external-internal gear pairs (meshing pinion and ring gear). For many applications, using the high point of single tooth contact (HPSTC) to locate the position of the tooth force is adequate for assessing the maximum tooth root stress condition. But for aerospace gearing such an approach may be inadequate for assessing the stress condition while also simultaneously minimizing mass. In this work specialized contact analyses and finite element methods were used to study gear tooth stresses of body flap actuator gears. The analytical solutions considered the elastic deformations as an inherent part of the solutions. The ratio for the maximum tooth stresses using the HPSTC approach solutions relative to the contact analysis and finite element solutions were 1.40 for the ring gear and 1.28 for the pinion gear.
\end{abstract}

\section{INTRODUCTION}

For aerospace applications there is a high premium on minimizing the mass of all components while meeting operational and safety requirements. Gears for space shuttle orbiter actuators were specified to meet safety factor requirements for fatigue life, yield, and ultimate load carrying capacity [Ref. 1]. Analytical predictions of safety factors for gear teeth with respect to yield, fatigue, and ultimate load capacity required careful assessment of the stress condition in the gear teeth root and fillet regions.

For a given torque applied to a gear, the stress in the tooth root and fillet region will be strongly influenced by the magnitude and location of the transmitted force. The sensitivity of the stress condition to the location of the force on the tooth flank can be envisioned by considering the gear tooth as a short cantilevered beam. For most gear design, one usually considers that the maximum stress on a gear tooth will occur when the gear tooth is in contact at the theoretical high point of single tooth contact (HPSTC). The theoretical HPSTC is determined from the undeformed gear geometry and it defines the largest radial distance for which the gear tooth is in contact without neighboring teeth in contact. For many gear design situations, the stress determined at the HPSTC provides a sufficiently accurate estimate of the most severe root-fillet stress condition. However, for the case of very heavily loaded gearing, the influence of elastic deformations can be substantial, and the estimated stress condition based on the HPSTC may be highly conservative for the purposes of meeting strength design constraints while simultaneously minimizing mass.

Body flap panels of space shuttle orbiters were positioned by heavily-loaded geared actuators. Using the HPSTC approach to estimate the maximum stress condition for this application provided a conservative estimate of the load carrying capacity of the gears and did not account for the influence of elastic deformations on tooth load sharing. One evaluation of the design considered that the load sharing effect on maximum fillet stress would likely be in the range of $15 \%$ to $20 \%$, and perhaps even higher [Ref. 2]

Ultimate strength of single gear teeth loaded at the pitch point have been reported by Moore [Ref. 3]. He reported that for 9310 case-carburized gears, the weakest of eleven teeth cracked when loaded to a stress of $308 \mathrm{ksi}$ (2.12 GPa) as calculated by the American Gear Manufacturers Association method. Although not stated by Moore, data are provided to allow calculation of the mean value of stress for cracking as $366 \mathrm{ksi}(2.52 \mathrm{GPa})$ and the largest value of stress for cracking 
as 2.81 GPa (407 ksi). Moore's study, including his review of the literature, provides direct data and guidance only for external-external gear pairs having teeth of standard proportions. The most heavily loaded gear teeth of the shuttle body flap actuator had been determined by analysis to be an external-internal gear mesh (a planet and ring gear mesh of a differential planetary gearing arrangement). The tooth-to-tooth load sharing effect could be expected to differ for an internalexternal mesh relative to an external-external mesh [Ref. 3]. The orbiter actuator planet and ring gear designs were nonstandard tooth proportions. To best assess the stress condition, a dedicated study was completed employing a special gear analysis tool [Ref. 4]. The position and shape of the contact pressure distributions on the gear teeth were determined considering the elastically deformed geometry. The tooth-to-tooth load sharing effect was inherently a part of the solution

\section{DESCRIPTION OF THE GEARS}

The orbiter body flap actuator is a two-stage gear design (Fig. 1) consisting of a planetary stage and a differential planetary stage. The most heavily loaded gear teeth of the system are the planet gear and ring gear mesh of the center housing [Ref. 5]. The planet gear is an 18 tooth, 12 pitch external involute gear. The internal gear of the housing assembly is an 81 tooth, 12 pitch internal involute ring gear. For this study the limit load (maximum torque) for the actuator was considered to be 335,000 in-lb $(37,818 \mathrm{~N}-\mathrm{m})$ of torque applied to the ring gear. The gear material was case carburized AISI 9310 steel.

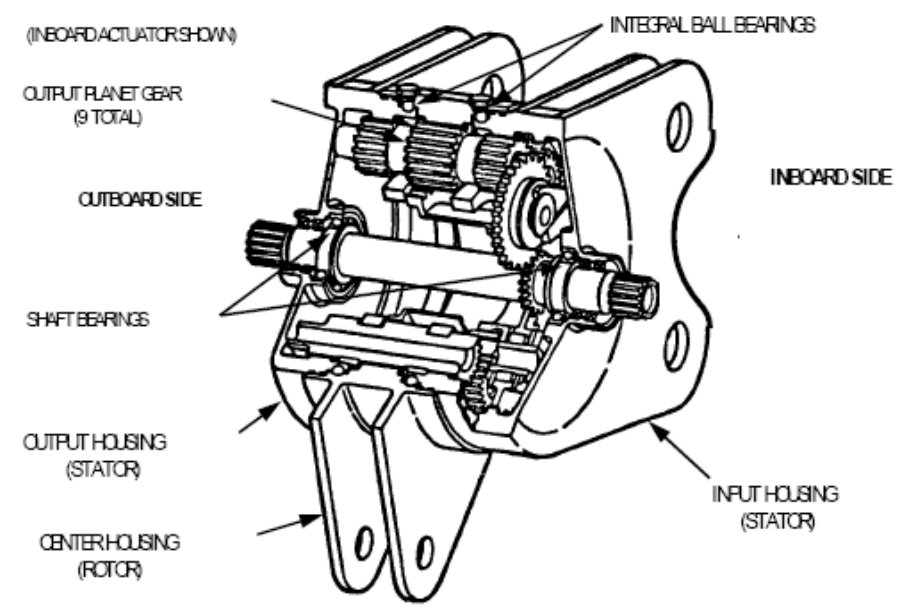

Fig. 1. Cutaway view of a body flap actuator unit.

\section{ANALYTICAL APPROACH TO CALCULATE GEAR TOOTH LOADS AND STRESSES}

A three-dimensional system-level analysis and a twodimensional tooth loading analysis, both using the finite element method, had been used to determine stresses of body flap actuator gear teeth [Ref. 5]. The model was used to determine the torque distributions among the nine planets of the differential planetary gearset and the contact load distribution shapes across the face widths of the gear teeth. The finite element solutions were obtained using boundary conditions and contact algorithms that assumed only one tooth on each gear was in contact. The finite element mesh employed was too coarse to accurately assess the stresses in the gear fillet and root regions. The system-level model was used to determine the most heavily loaded gear mesh. To make use of these results to determine gear fillet stresses, a separate two-dimensional finite element model of the gear teeth was created. The loads applied to the two-dimensional model were determined using the analysis results for tooth forces as determined from the threedimensional system level analysis. The loads were applied to the gear teeth of the two-dimensional model at the highest point of single tooth contact.

The analysis approach as described in the preceding paragraph provided a conservative assessment of the working stresses of the gear teeth. Although certain system-level effects were captured using the three-dimensional model, tooth-totooth load sharing effects were not captured since loads were assumed to be carried by a single tooth on each gear. This approach was taken to obtain solutions given limits of the general purpose finite element solver, computing processor speed, and computer memory. To make best use of the existing system level analysis results while also assessing the influence of tooth-to-tooth load sharing, the following approach was followed and employed for the work reported herein: 
1. Create a two-dimensional finite element analysis model of the meshing gears

2. Calculate maximum gear tooth fillet stress for case of load carried by one tooth at the theoretical HPSTC

3. Using the same finite element analysis model, calculate maximum gear tooth fillet stresses allowing for multiple teeth to carry the load depending on the deformed gear geometry and the angular positioning of the gears (model of meshing gears).

4. Calculate a correction factor (C.F.) using the ratio of the stresses as determine by steps 2 and 3 above.

5. Determine the correction factor as a function of applied torque such that the correction factor can be applied to previous stress analysis results that were based on loads applied at theoretical HPSTC.

\section{Analytical Model of the Meshing Gears}

The body flap actuator was studied to determine estimates of the tooth fillet and root stresses as a function of the torque applied to the center housing (rotor ring gear). The stress was estimated using a two-dimensional finite element based, multibody contact analysis algorithm [Ref. 4]. This approach makes no prior assumptions about the distribution of forces and contact pressures on the gear teeth. The bending deformations of the gear teeth are determined using finite element formulations and a combined surface integral/finite element solution is used to determine contact deformations and contact pressures on the gear teeth. Candidate points of contact are found from undeformed gear geometry, then a quadratic programming technique solves for contact positions on deformed gear geometries.

Analytical models of the gears were developed using information from manufacturing blueprints. The model was developed using the following approach:

- nominal dimensions were used for gear tooth geometry unless otherwise specified

- nominal dimension was used for the gear center distance

- maximum tolerance value was used for planet gear tooth root diameter

- minimum tolerance value was used for ring gear tooth root diameter

- minimum tolerance value was used for the planet gear outer diameter, with adjustment to include edge break

- maximum tolerance value was used for the ring gear inner diameter, with adjustment to include edge break

- the hob tip radius assumed was the maximum radius that would permit manufacture of the gears
- tip relief for the planet gear was modeled using a quadratic shape modification and having magnitude per the nominal amount from the drawing

- nominally zero spacing errors was assumed for the purpose of calculating correction factors; spacing error effects were studied separately

- nominally zero friction was assumed for the purpose of calculating correction factors; friction effects were studied separately

- the material was assumed to respond elastically having Young's modulus equal to 30 million lb/in2 (207 GPa) and Poisson's ratio equal to 0.3

This approach produced a model with maximum tooth stiffness, thereby providing for a somewhat conservative estimate of the correction factor.

The planet gear and center housing finite element model is illustrated in Figure 2. The ring gear housing model had a constant-valued outer dimension. There was no attempt to capture localized stiffening effects of gussets and other housing structure about the outer diameter as was important for the fullsystem model that as used to estimate planet-to-planet torque distributions. A close-up of the finite element mesh is provided in Figure 3. The tooth flanks are comprised of specialized finite elements having nonlinear shapes with established radii of curvatures and orientations of the surface normals as required for the numerical contact analysis. The elements in the root and fillet regions are third order elements. Figure 3 accurately depicts the finite element mesh and the corner nodes but does not depict the additional nodes of the high-order finite elements. The adequacy of the finite element mesh density has been studied using convergence studies [Ref. 6].

The ring gear was defined as the input member with the torque applied to the ring outer diameter as a mathematical boundary condition. The planet gear inner diameter was constrained using a mathematical zero-rotation boundary condition. The ring gear outer diameter and the planet gear inner diameter were modeled as elastic bodies having a shape described by a Fourier series of order 9 with the rigid body displacement terms set equal to zero. Figure 3 depicts the gear geometry without elastic deformations. The points on gear teeth in contact at low torque for this orientation of the gear pair is highlighted by a circle (lower circle). With sufficient elastic deformation, a second pair of gear teeth will come into contact (upper circle). 


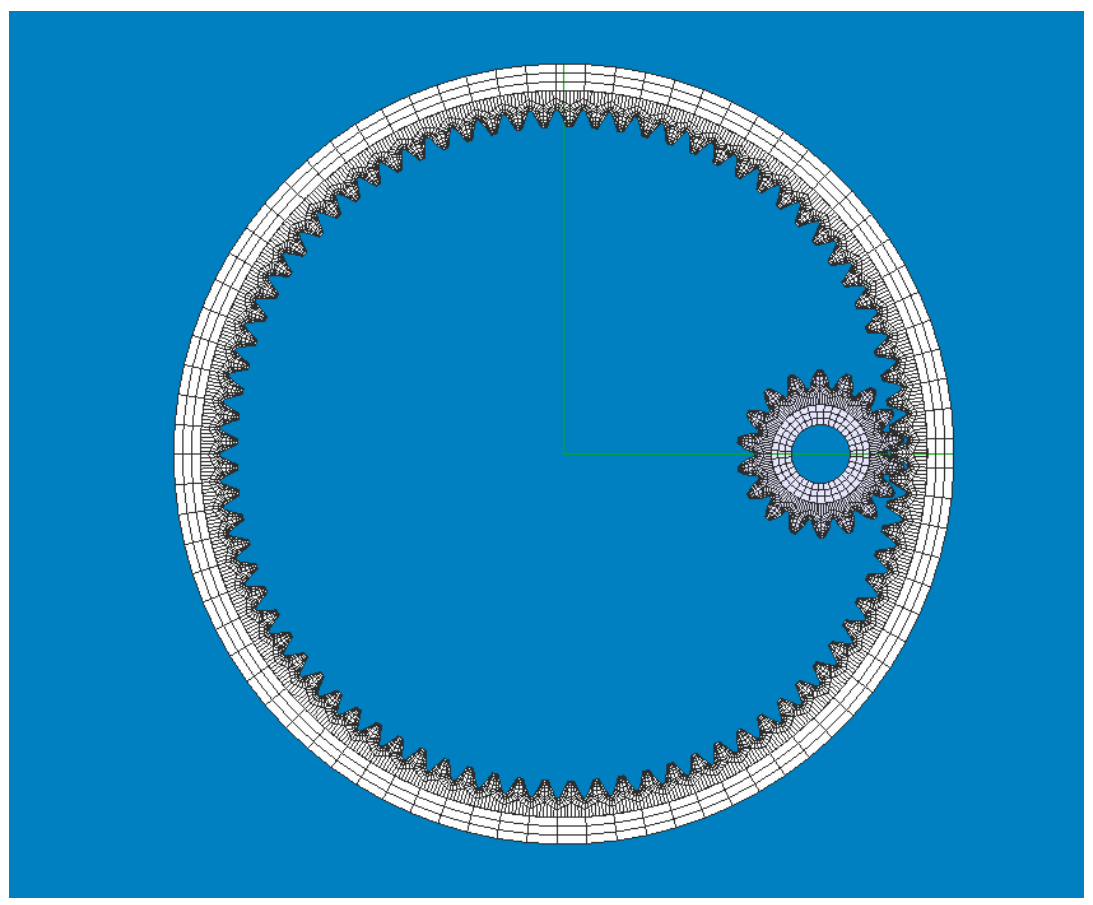

Figure 2. OVERALL VIEW OF THE FINITE ELEMENT MODEL TO STUDY THE BODY FLAP ACTUATOR COMPRISING A PLANET GEAR MESHING WITH THE CENTER HOUSING RING GEAR

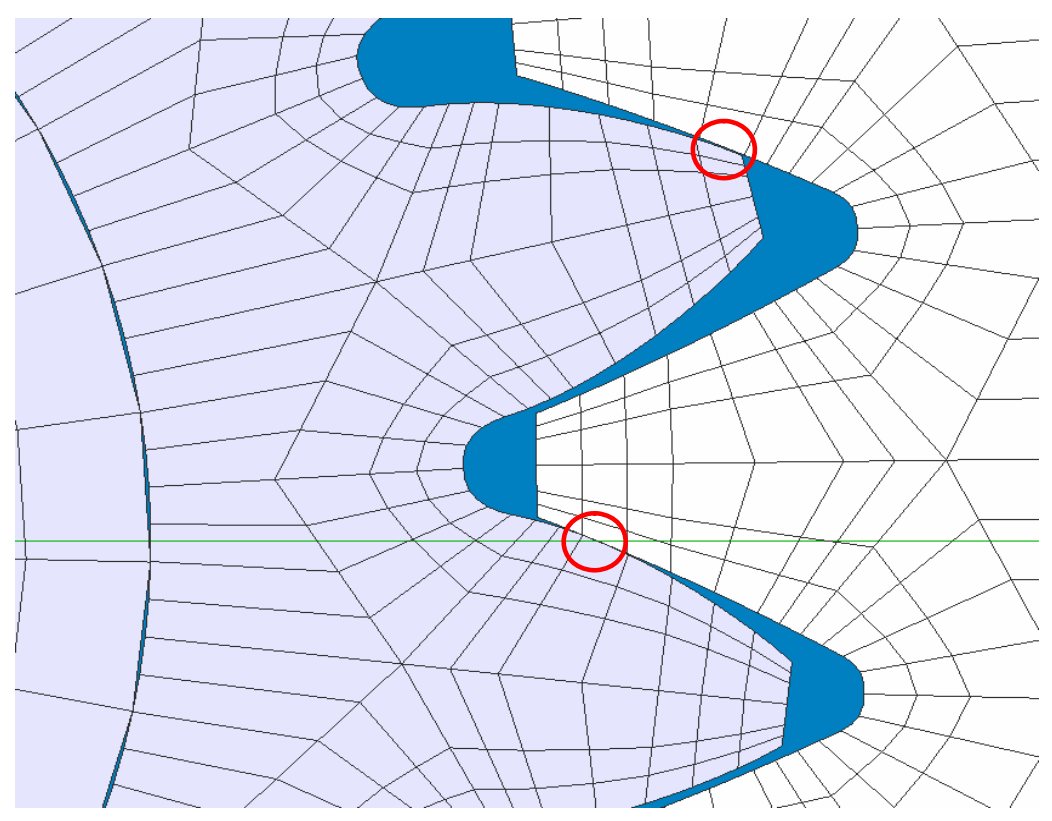

Figure 3. CLOSE-UP VIEW OF THE FINITE ELEMENT MODEL OF A PLANET GEAR MESHING WITH THE CENTER HOUSING RING GEAR 
The finite element model was two dimensional and can be thought of as an analysis on a "per unit" basis in the direction of the gear face width. The physical system has nine planets engaging the ring gear. The planets have unequal torque sharing owing to the differing backup structure about the ring gear. The planet-to-planet load sharing has been estimated using a system-level three dimensional finite element model [Ref 5.]. The applied torque for the finite element ring gear to simulate the most heavily loaded of the nine planets for the system limit load was calculated by

$$
\begin{aligned}
& \text { Torque }(\text { in } \cdot l b)=\frac{335000 \times 1.27}{9 \times 1.133} \\
& \text { where } \\
& 1.27 \text { accounts for planet to planet load sharing } \\
& 9 \text { accounts for the nine planets } \\
& 1.133 \text { accounts for the average gear facewidth (inch) }
\end{aligned}
$$

Equation 1 defines the torque applied to the finite element model to simulate the most heavily loaded planet for the "limit load" flight condition. To assess the "ultimate load safety factor", analyses were done for torques up to 1.4 times the limit load torque.

The analytical model was used to study the stress conditions of the gear teeth. The contact analysis algorithm requires selecting values of three key parameters for the contact solution. These parameters trade-off the resolution of the contact distribution with the computing resources (time and memory) required to perform the iterative computations. The following list describes the parameters and values used for the present work.

1. The "separation tolerance" parameter influences whether or not candidate surfaces should be checked for contact. Using the un-deformed geometry, a onetime check is made to determine whether or not particular contact cells might come into contact with another surface. Too small a value of the "separation tolerance” parameter eliminates contact cells from the solution even though the deformations under load would allow the cell to come into contact. Therefore, for too small a value for the "separation tolerance", the predicted contact area is too small. Too large a value of the "separation tolerance" parameter requires excessive computing time and memory since many candidate cells are checked for each iteration even though contact will not be possible. For the present study, a separation tolerance parameter value of 0.010 inch was employed for all analyses.

2. The "nprofdivs" parameter sets the number of contact patches (discretization) for each candidate contact surface. Too small a value of the "nprofdivs" parameter results in a predicted contact pressure distribution having poor resolution. Too large a value of the "nprofdivs" parameter requires excessive computing time and memory. For the present study, a "nprofdivs" parameter value of 25 was employed for all analyses, defining 51 potential contact cells on each gear tooth.

3. The "dsprof" parameter controls the width of the contact zone as declared using local surface units [Ref. 4]. Too small a value of the "nprofdivs" parameter results in inaccurate pressure distribution solutions. Too large a value of the "dsprof" parameter results in a predicted contact pressure distribution having poor resolution. Table 1 provides the values used for the "dsprof" parameter as a function of the torque loading.

Table 1. CONTACT ALGORITHM PARAMETER "DSPROF” VALUES USED FOR THE PRESENT WORK

\begin{tabular}{|c|c|}
\hline $\begin{array}{c}\text { Torque } \\
\text { (normalized to limit load } \\
\text { torque) }\end{array}$ & $\begin{array}{c}\text { Value of the } \\
\text { "dsprof” parameter }\end{array}$ \\
\hline 0.002 & 0.015 \\
\hline 0.063 & 0.075 \\
\hline 0.125 & 0.100 \\
\hline 0.250 & 0.150 \\
\hline 0.500 & 0.200 \\
\hline 1.000 & 0.300 \\
\hline 1.400 & 0.400 \\
\hline
\end{tabular}

\section{Analysis Results}

The body flap actuator was studied to obtain estimates of the tooth fillet and root stresses as a function of the torque applied to the center housing (rotor ring gear). Details of typical analysis results and summary information will be discussed concerning the influence of torque, spacing errors, and friction on the gear tooth fillet stress.

The predicted contact pressure distributions were plotted for each contact analysis to assess the precision of the contact solution. Vijayakar [Ref. 4] provides guidance for assessing the contact pressure solutions. Figure 4 displays a typical contact pressure distribution result for this study. Note that the pressure distribution deviates slightly from the symmetric pressure distribution of a classical Hertzian contact analysis. The Hertzian approach uses a simplified description of the contacting surfaces as having a single value for radii of curvature. The present analysis accounts for varying radii of curvature as a function of position within the contact.

To determine the gear orientations that produced the maximum fillet stress for one ring gear torque, a set of static analysis solutions were completed to simulate the rotation of the planet gear pinion. A sufficient number of analyses were done to resolve the planet gear rotational orientation that produced the largest stress to within 0.020 degrees of rotation.

The effect of elastic deformation on the loading of individual gear teeth is illustrated in Fig. 5. Here, the load on an individual gear tooth is plotted as a function of the rotation of the planet gear for the case of a lightly loaded gear pair $(0.2 \%$ of limit load torque) and heavily loaded gear pair (limit load 
torque). The tooth load data of Fig. 5 have been normalized relative to the tooth load required to produce the torque for each of the two analysis cases. As shown in the figure, the gear tooth load histories differ significantly for heavily loaded relative to lightly loaded gear pairs. For the lightly loaded condition, the maximum tooth load occurs during a significant

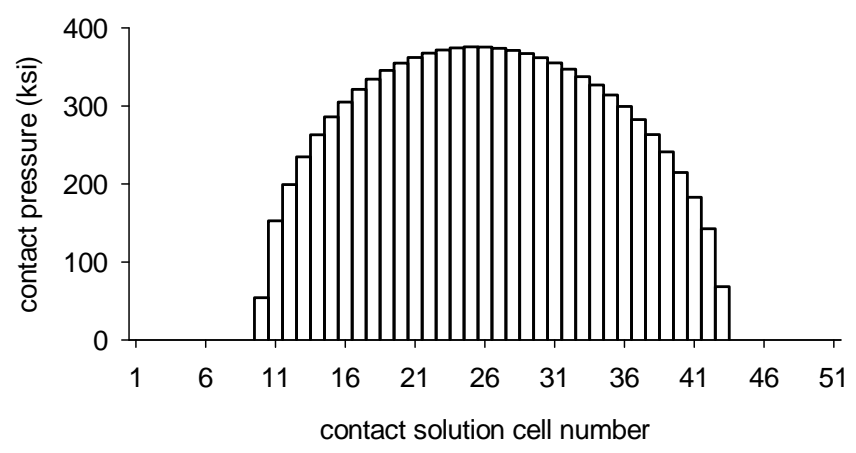

Figure 4. EXAMPLE OF CONTACT PRESSURE DISTRIBUTION SOLUTION. THE CONTACT AREA WAS SETUP USING 51 CONTACT CELLS. CELLS HAVING ZERO PRESSURE ARE NOT IN CONTACT WITH THE MATING GEAR TOOTH

To relate the influence of elastic deformation to the load carrying capability of gear teeth, the stresses in the tooth fillet and root regions were studied. Figure 6 illustrates the stress distribution for a heavily loaded gear pair and Figure 7 illustrates the maximum principal stress distribution for the

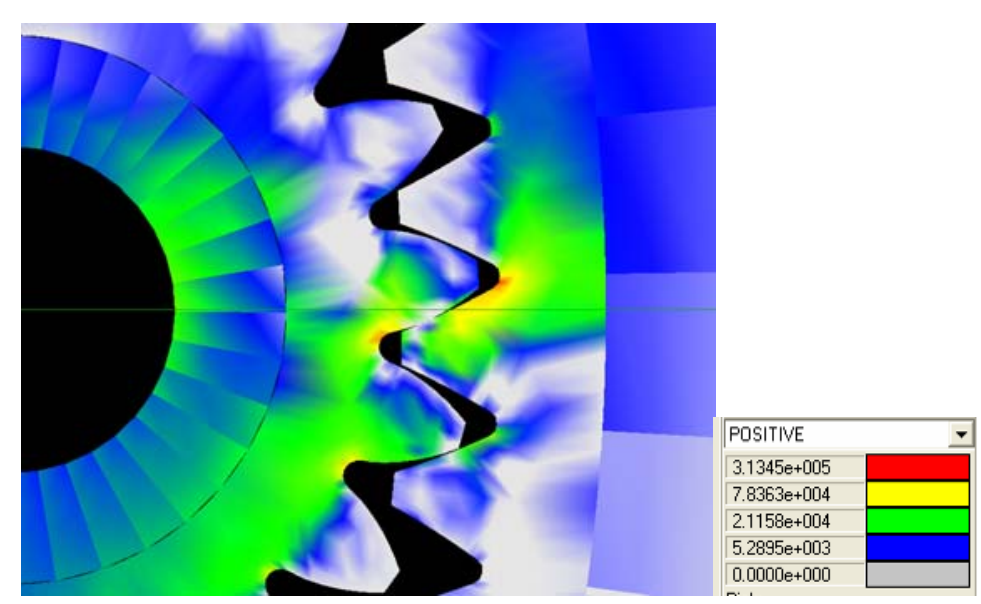

Figure 6. DISTRIBUTION OF MAXIMUM PRINCIPAL STRESS (LB/IN²) FOR A HEAVILY LOADED GEAR PAIR. portion of the base pitch of rotation, and the maximum load will occur very near the high point of single tooth contact. For the heavily loaded condition, the maximum tooth load occurs for a very small portion of the base pitch of rotation and the maximum load will occur near the tooth mid-height.

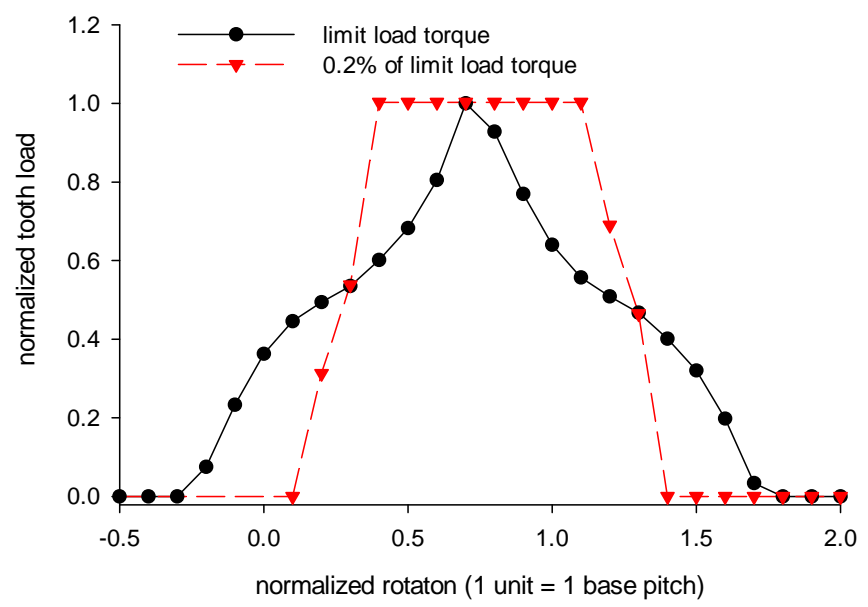

Figure 5. LOAD HISTORY OF A SINGLE GEAR TOOTH FOR CASES OF LIGHT AND HEAVY TORQUE LOADS

external gear with the deformations exaggerated by a factor of 20. From Fig. 7 one can observe that the total compliance of the gear pair includes influences of gear body tending toward an oval shape, gear tooth surface deformation, and gear tooth bending.

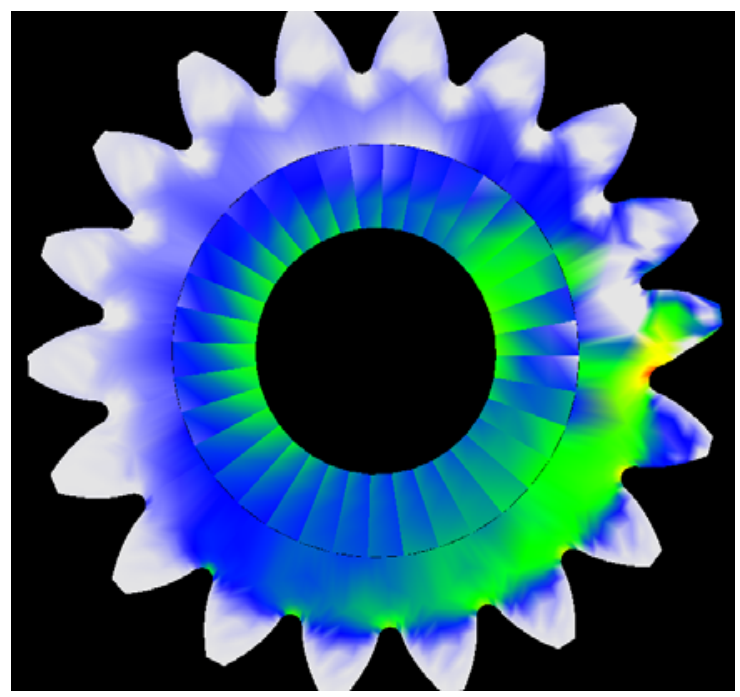

Figure 7. MAXIMUM PRINCIPAL STRESS DISTRIBUTION ILLUSTRATED ON THE DEFORMED GEOMETRY, WITH DEFORMATIONS EXAGGERATED BY A FACTOR OF 20. THE STRESS MAGNITUDE EQUALS THE SCALING OF FIG. 6 
The maximum principal stress for one ring gear tooth fillet region as a function of the rotation of the gear for a heavy torque load is illustrated in Figure 8. The peak stresses as predicted using both the FEA/contact analysis and the HPSTC method are given. One can see that the predicted rotational positions for the maximum stress differ significantly for the FEA/contact analysis method and the HPSTC method. In this example, the value of the largest tooth load is the same for the FEA/contact and HPSTC methods, but the FEA/contact method predicts that the maximum tooth load occurs on the tooth flank somewhat closer to the base as compared to the HPSTC method. The predicted worst-case stress condition is significantly less for the FEA/contact method compared to the HPSTC method.

A series of analyses were completed to understand the influence of applied torque on the stress conditions of the gear teeth. The finite element analyses results were processed to obtain the maximum principal stress invariant and the maximum Von Mises stress invariant for the fillet regions of the entire gear for each analysis. Stresses were determined for both the FEA/contact analysis method and the HPSTC method. Table 2 (planet gear) and Table 3 (ring gear) provide a summary of the calculated stresses. The "correction factor" column is the ratio of the stress as would be predicted by the HPSTC method divided by the solution using the FEA/contact analysis method. The correction factor data highlight that for this gearset the HPSTC method provides a highly conservative estimate of the maximum tooth stress. Figure 9 plots the data from Tables 2 and 3 showing the trend of the FEA results as a function of applied torque. For smaller torques the ring gear is the more highly stressed member but for larger torques the planet gear is the more highly stresses member. Figure 10 provides the correction factors as functions of ring gear torque. The correlations are nonlinear

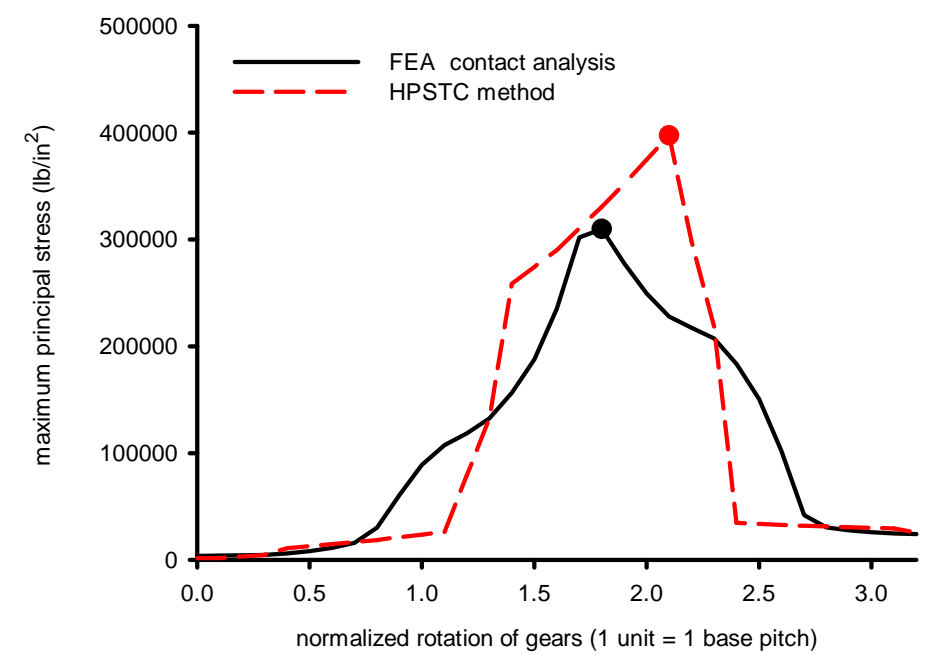

Figure 8. TWO METHODS TO PREDICT THE MAXIMUM PRINCIPAL STRESS FOR A SINGLE GEAR TOOTH FILLET REGION FOR THE HEAVILY LOADED RING GEAR FOR LIMIT LOAD TORQUE

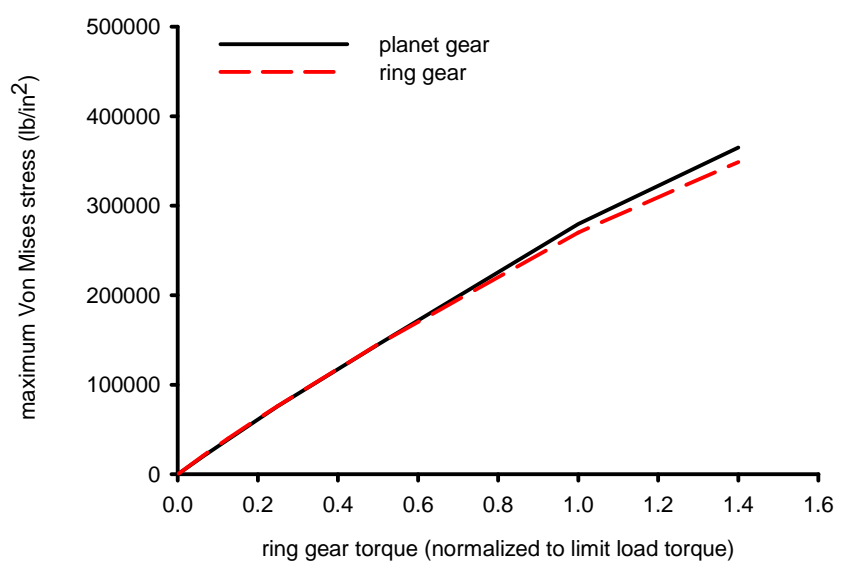

Figure 9. TREND OF MAXIMUM VON MISES STRESS IN THE FILLETS OF THE PLANET AND RING GEARS AS A FUNCTION OF APPLIED TORQUE AS PREDICTED BY THE FEA CONTACT ANALYSIS METHOD 
Table 2. SUMMARY OF ANALYSIS RESULTS FOR THE PLANET GEARS

\begin{tabular}{|c|r|r|c|}
\hline $\begin{array}{c}\text { Torque } \\
\text { (fraction of limit load) }\end{array}$ & $\begin{array}{c}\text { Maximum } \\
\text { principal stress } \\
\text { (psi) }\end{array}$ & $\begin{array}{c}\text { Maximum Von Mises } \\
\text { stress } \\
\text { (psi) }\end{array}$ & $\begin{array}{c}\text { Correction factor for } \\
\text { Von Mises stress }\end{array}$ \\
\hline 0.002 & 902 & 782 & 1.000 \\
\hline 0.062 & 22,892 & 19,775 & 1.054 \\
\hline 0.125 & 44,610 & 38,606 & 1.080 \\
\hline 0.250 & 86,853 & 76,200 & 1.094 \\
\hline 0.500 & 167,912 & 144,912 & 1.150 \\
\hline 1.000 & 324,424 & 279,558 & 1.193 \\
\hline 1.400 & 424,094 & 365,096 & 1.279 \\
\hline
\end{tabular}

Table 3. SUMMARY OF ANALYSIS RESULTS FOR THE RING GEARS

\begin{tabular}{|c|r|r|c|}
\hline $\begin{array}{c}\text { Torque } \\
\text { (fraction of limit load) }\end{array}$ & $\begin{array}{c}\text { Maximum } \\
\text { principal stress } \\
\text { (psi) }\end{array}$ & $\begin{array}{c}\text { Maximum Von Mises } \\
\text { stress } \\
\text { (psi) }\end{array}$ & $\begin{array}{c}\text { Correction factor for } \\
\text { Von Mises stress }\end{array}$ \\
\hline 0.002 & 977 & 819 & 1.000 \\
\hline 0.062 & 24,411 & 20,486 & 1.065 \\
\hline 0.125 & 47,393 & 39,785 & 1.097 \\
\hline 0.250 & 90,920 & 76,353 & 1.143 \\
\hline 0.500 & 172,621 & 145,300 & 1.202 \\
\hline 1.000 & 322,637 & 270,263 & 1.292 \\
\hline 1.400 & 416,634 & 349,008 & 1.401 \\
\hline
\end{tabular}

The results of the stress analyses just discussed were completed assuming zero friction. However, it is known that friction can influence gear tooth stresses. To assess the influence of friction, the stress of the planet gear was determined assuming a coulomb friction coefficient of 0.1 for the case of limit load torque. Analyses were done both for the case of panel closing motion (panel motion in the direction of air loads) and for panel opening motion (panel motion opposite the direction of air loads). The analyses completed were for the static case (no motion) simulating the condition of impending motion. The predicted maximum principal tensile stresses in the gear root and fillet region are provided in Fig. 11. Note that the ratio of the stresses from analysis accounting for friction relative to no friction is about 1.12 for a friction coefficient of 0.1 and panel opening motion. For the case of panel closing motion, the ratio of stresses is about 0.86. The influence of friction on the absolute stress value is significant and should be considered for purposes of validation testing.

The results of the stress analyses discussed so far assume zero tooth spacing errors on any gear. Spacing errors are known to influence dynamic tooth forces, especially for high speed gears and lightly loaded running gears. However, for the subject application the motions are slow and the loads of interest are high. Therefore, one can anticipate that the influence of spacing errors would be small. One analysis case was conducted to confirm this anticipated result. The maximum permitted spacing error was modeled on one tooth of the planet gear. The load case was limit load torque with zero friction. Analyses were done to simulate the motion of the planet through several base pitches of rotation to include contact on the tooth preceding and the tooth following the one having spacing errors. The tooth stresses for cases with and without tooth spacing errors were the same to within accuracies of any engineering significance.

The analyses results summarized so far have presented maximum stress values. That is, for any analysis case for a particular torque and gear orientation, the maximum stress for any position in the fillet was determined. The stress experienced by a particular point on the gear body can also be assessed using the finite element analysis tool. Particular positions along the planet gear teeth fillets were selected to illustrate the trend. The results provided in Fig. demonstrate that the stress is a strong function of the gear rotation position. Such a behavior should be considered for purposes of validation testing. 


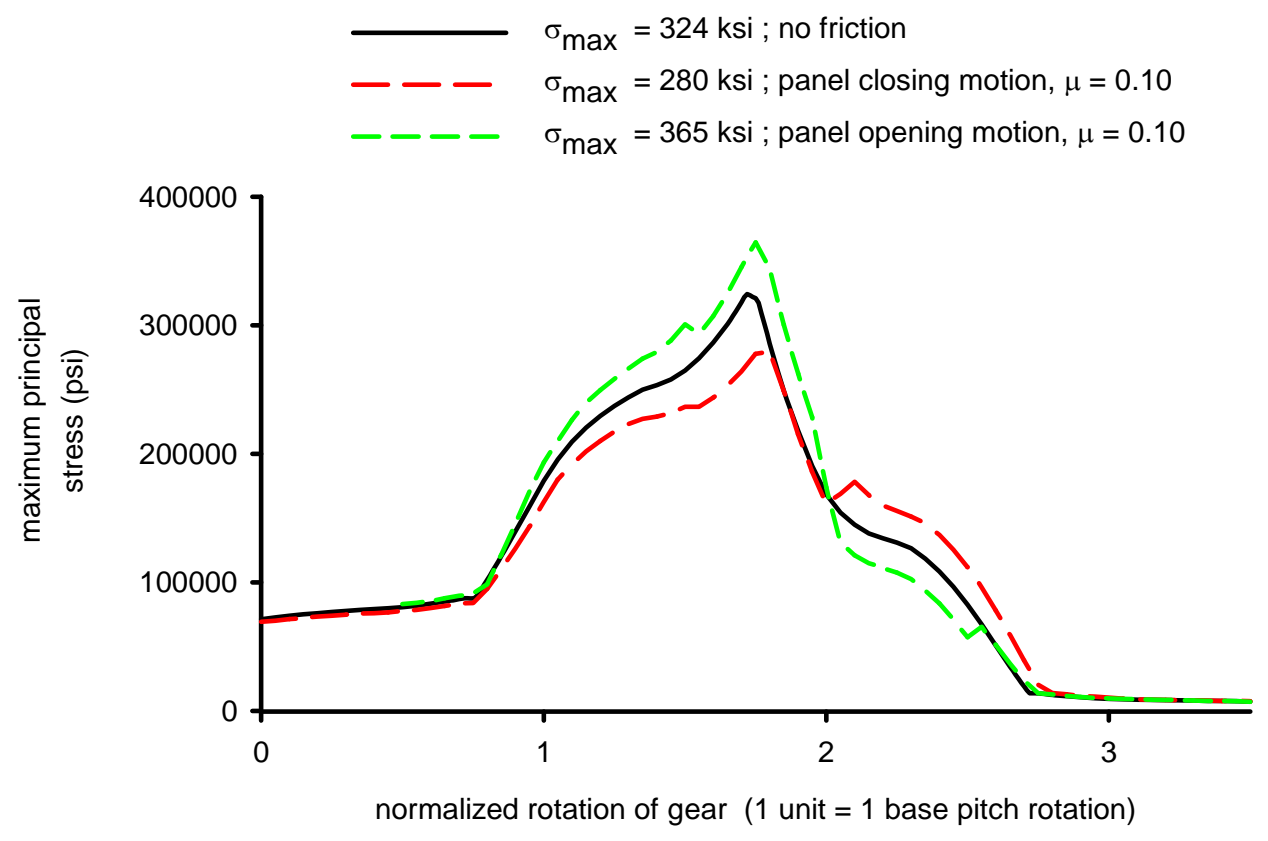

Figure 11. INFLUENCE OF FRICTION ON THE MAXIMUM PRINCIPAL TENSILE FILLET STRESS FOR THE PLANET GEAR FOR THE CONDITION OF LIMIT LOAD TORQUE AND COULOMB FRICTION OF 0.1

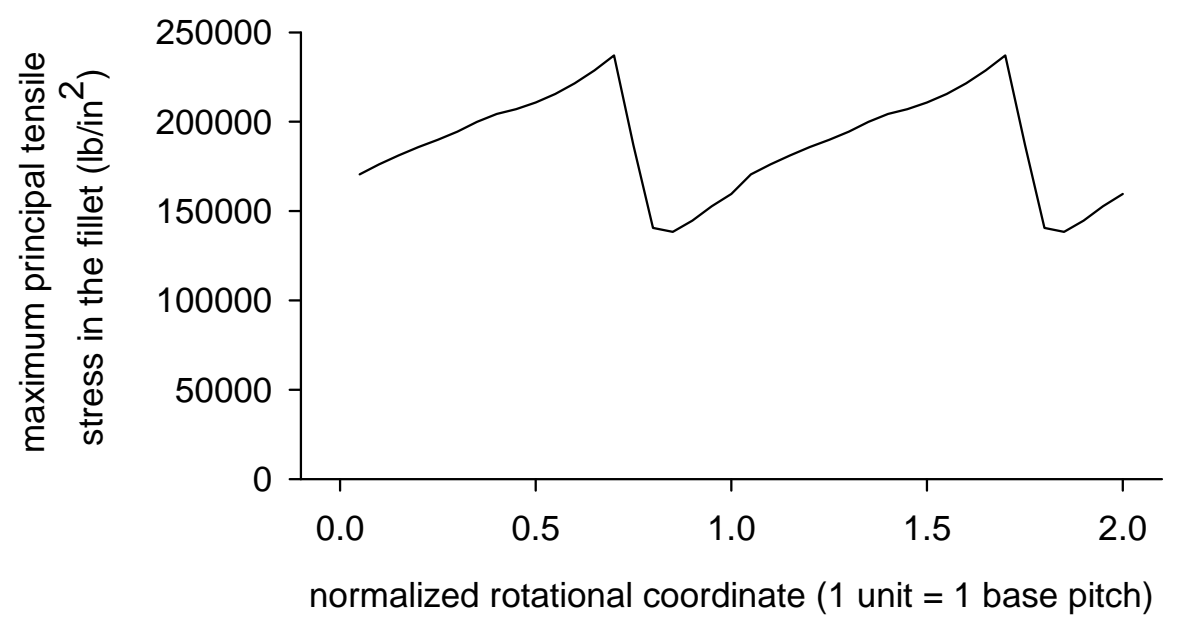

Figure 12. TREND OF PRINCIPAL TENSILE FILLET STRESS FOR PARTICULAR POSITIONS ON THE FILLET REGIONS OF THE PLANET GEAR TEETH AS A FUNCTION OF GEAR ROTATION FOR CASE OF LIMIT LOAD TORQUE. 


\section{SUMMARY OF RESULTS}

The orbiter body flap actuator was presented as a case study to determine estimates of the tooth fillet and root stresses of a very heavily loaded pinion-ring gear mesh. The analysis used was a multi-body contact analysis approach employing finite element methods. The elastic deformations of the gear bodies and gear teeth were inherently a part of the solutions. The results were compared to the stresses as calculated using a high point of single tooth contact (HPSTC) analysis method. The following significant results were obtained.

1. The HPSTC method provides very conservative estimates of the maximum stress conditions for highly loaded gear pairs.

2. For the ultimate load condition representing 1.4 times the limit load torque, the ratio of the maximum Von Mises stresses for the ring gear as predicted by the HPSTC method and by the finite element contact analysis method was 1.40 .

3. For the ultimate load condition representing 1.4 times the limit load torque, the ratio of the maximum Von Mises stresses for the planet gear as predicted by the HPSTC method and by the finite element contact analysis method was 1.28.

4. The influence of friction on the maximum tooth stresses is significant.

5. The influence of spacing errors on the maximum tooth stresses for the subject gear pair was negligible.

6. The maximum tooth stress is a strong function of the gear rotation position.

\section{ACKNOWLEDGMENT}

The authors are grateful for the financial, technical, and administrative support of this work provided by the NASA Engineering and Safety Center.

\section{REFERENCES}

[1] The Boeing Company, 2002. Human Space Flight and Exploration, Specification, Actuation Subsystem, Body Flap, MC621-0056, Rev. C.

[2] Drago, R., 2005. Boeing Orbiter Body Flap Gears, Tooth To Tooth Load Sharing Due to Tooth Elastic Deflections, DST 1055, memo to the Boeing Company, June 29, 2005.

[3] Moore, W. L. 1979. Low-Cycle Fatigue and Ultimate Strength Related to Gear Design, ASME J. of Mechanical. Design, Vol. 101.

[4] Vijayakar, S., 2003. Multi-body Dynamic Contact Analysis Tool for Transmission Design - SBIR Phase II Final Report, ARL CR-487.

[5] Hill, D., 2005. Space Shuttle Body Flap Actuator Stress Analysis Summary - Revision C, presentation material, Hamilton Sundstrand Company, Rockford, Ill.

[6] Vijayakar, S. 2003. Helical3D Validation Manual, Advanced Numerical Solutions, Hilliard, Oh. 